\title{
Supporting Literacy of English Language Learners in Mainstream Classrooms
}

\author{
${ }^{* 1}$ Firman Parlindungan, ${ }^{2}$ Refanja Rahmatillah \\ *11 Universitas Teuku Umar, Indonesia, firman@utu.ac.id \\ ${ }^{2}$ Universitas Teuku Umar, Indonesia, refanjarahmatillah@utu.ac.id
}

Submitted: 20/09/2020 Revised: $31 / 10 / 2020 \quad$ Accepted: $26 / 11 / 2020$

How to cite this article: Parlindungan, F. \& Rahmatillah, R. (2020). Supporting literacy of English language learners in mainstream classrooms. International Journal of Education, Language and Religion, 2(2), 102-111. http://dx.doi.org/10.35308/ijelr.v2i2.5065

\begin{abstract}
English language learners (ELLs) may not yet be proficient enough to participate in a mainstream classroom in the U.S. schools, and they often feel anxious, frustrated, and embarrassed. Identifying best instructional practices to foster literacy learning of ELLs has been an urgent priority in research given the fact that the ELLs population continues to increase. Teachers in the U.S classrooms need to be equipped with sufficient knowledge and skills to meet the needs of these students. In this paper, current understanding of teaching literacy to ELLs in elementary classroom is presented, which revolve around discussion of oral language, complex text, and teacher engagement which is both culturally and linguistically relevant.
\end{abstract}

\section{Keywords}

literacy; English language learners; mainstream classroom

\section{Introduction}

It has widely known that English language learners (ELLs) may not have full participation in a mainstream classroom due to multiple factors. Those factors may include limited oral language proficiency (August \& Shanahan, 2006; Flynn, 2007; Quiros et al., 2012), limited access to the target language culture (Drucker, 2003; Hite \& Evans, 2006; Toppel, 2015), and limited support to engage with more complex texts (Iddings, Risko, \& Rampulla, 2009; Kibler, Walqui, \& Bunch, 2015).

The trend is even worse with a shift of the U.S. educational landscape towards high-stakes testing and curricular standardization in which ELLs are framed as "at-risk" of school failure. Their cultural and linguistic barriers are also viewed as deficit (Ghiso \& Low, 2012). Instead of acknowledging ELLs' social dimensions as 'the funds of knowledge' (Gonzalez, Moll, \& Amanti 2005), school policies and practices provide little space for these students to learn and articulate their own narratives as members of the learning community.

Martinez, Haarris, and McClain (2014) previously conceptualized some ideas that may become best practices to help ELLs in the classroom context, including (1) developing academic English at all stages of second-language acquisition, (2) conducting frequent formative reading assessments to drive 
instruction with some accommodations as needed, and (3) using small groups and peer-assisted methods in a safe learning environment.

Indeed, as demonstrated in other research, ELLs may need some adjustments of instruction to be able to access the material being learned, which may include particular emphasis on certain components of literacy (e.g. vocabulary), English grammar, and cultural relevance (Avaloz, Plasencia, Chavez, \& Rascon 2007), or an extra emphasis on oracy through talk-rich environment (Flynn, 2007).

\section{Method}

In the following, we present current understanding of working with ELLs in a mainstream classroom by exploring research on the issues relative to the English language and literacy learning of ELLs in elementary classroom and the ways teachers should engage with them to support the development of both areas. We elucidate three major themes, including: (1) supporting students to read complex text, (2) making connection between the students' culture and the target culture, and (3) strengthening academic language. Each theme is discussed consecutively in line with the contexts and empirical evidences supporting it.

\section{Results and Discussion}

\section{Supporting Students to Read Complex Text}

Researchers to date have given a great deal of attention to the teaching of literacy in the mainstream classroom, especially by incorporating various types of texts to enrich the oral language and comprehension (e.g. DelliCarpini, 2008; Iddings et al., 2009; Kibler et al., 2015; Martin-Beltran, Tigert, Peercy, \& Silverman, 2017; Purdy, 2008). Since students in the mainstream classroom may comprise of diverse individual differences, incorporating texts that address these differences may be considerable. However, it may require hard work to have them engaging with the activities around the texts as has been mentioned earlier that one of the major challenges faced by some students is limited support dealing with complex texts.

\section{Characteristics of Complex Text}

It is important to discuss first what makes a text complex and what characteristics that quality texts have. Mesmer, Cunningham, and Hiebert (2012) mentioned that text complexity has been a central point on the Common Core State Standard (CCSS) for English Language Arts, but it has been absent in research community for several decades. They technically defined text complexity as opposed to text difficulty. To them, text complexity denotes text features that imply independent variables, such as textual elements or factors that can be analyzed, studied, or manipulated.

In contrast, text difficulty implies dependent variables, such as "the actual or predicted performance of multiple readers on a task based on that text or feature" (p. 236). Frantz, Starr, and Bailey (2015) defined text complexity as "the level of sophistication and challenges of a reading selection or other type of text" (p. 387). A model of text complexity in early grades according to Mesmer et al. (2012) consists of at least three main features: (1) word-level features covering structural complexity and familiarity, (2) syntax features covering average sentence length, and (3) discourse structure features covering cohesion, genre and text length.

Firstly, a good text complexity in early grades should contain repetition on rimes, bigrams, or vowel graphemes to allow students build oral reading accuracy and decoding with balanced number of new words and frequent familiar words. Secondly, word identification and meaning of vocabulary then should be placed in syntactic structure. It allows students to learn case relation among concepts represented by content words which may lead them to reading comprehension. 
Frantz et al. (2015) supported that syntactic structure should be included as an explicit and distinct component of text complexity given the fact that sentence structure contributes to the meaning of text, and grammatical meaning influences reading comprehension. Mesmer et al. (2012) however argued that there is a little agreement in research to date whether average of sentence length (number of words in the longest sentence) or T-unit length (number of independent clause and any dependent clauses attached) is an important determiner of text complexity in early grades books.

Thirdly, vocabulary and syntax of a text should be attached to the discourse structure which requires students to understand cohesion, genre, and length of text. It is clear that knowledge of cohesion contributes to reader's paragraph and discourse comprehension because cohesion makes a text easier to understand (Mesmer et al., 2012). Concerning the relation of genre and text complexity, it is still inconclusive whether certain genre of text is more challenging than the other. More research is needed in this regard.

For instance, Pyle, Vasquez, Kraft, Gillam, Reutzel, Olszewski, ... Pyle, et al. (2017) conducted a meta-analysis on the effects of expository text structure designed to improve reading comprehension of kindergarten to grade 12 students published between 1970 and 2013. They found significant contribution of expository text structure on reading comprehension with large effect sizes (.83). Similar findings have been demonstrated by Leighton, O'Brien, and Giunco (2017). Some research may also favor different genres for a variety of purposes used in multiple ways and contexts (Lefstein \& Snell, 2011). However, text length remains an important aspect to be considered in text complexity since greater length of text may increase the frustration and difficulty level of comprehension (Mesmer et al., 2012).

\section{Selecting Quality Text}

As has been pointed earlier in the previous section that the trends of text complexity in early grades tend to be more demanding in the last six decades (Fitzgerald et al., 2015), which mainly influenced by the educational policies and the advocacy of special interest groups to a greater degree than the evidence from theory and research (Mesmer et al., 2012). This condition indicates that educators need to take serious account in selecting texts for their students, especially those whose students are predominantly ELLs.

DelliCarpini (2008) suggested that main texts should be accompanied by supplemental readings as the abridged versions that may allow the teacher and the students to be involved in activities that make important connection between the text and their own cultural backgrounds, situate their background culture into the global context as portrayed by particular text, and share knowledge with peers in a way that improve their own background. We will discuss the significance of cultural information on the texts and its connection to the students' own culture in the next section. Our primary point here is that what kind of text to be learnt determines the success of the teaching and learning in the mainstream classroom.

\section{Initiating Talk to Provide Meaningful Interaction and Context}

Martin-Beltran et al. (2017) examined how a classroom with diverse cultural backgrounds engage with digital and paper books in a cross-age peer learning literacy program. The mixed method analysis revealed that students used digital and paper texts in distinct ways during their reading interactions with other students. Although the engagement (captured quantitatively by time sampling codes) was relatively equal across the two text types, the quality of engagement differed considerably.

While active engagement around the digital texts consisted mainly of tapping on the screen animations, active engagement with the books involved students more in the discussion around the text, and thus more opportunities for students to practice using language. Additionally, mediational 
episodes were generally longer and more in-depth when the students were using the paper texts. This finding contributes to the discussion of engagement beyond simply "active" and "passive" and the opportunities to use language as a way to understand quality engagement, especially among students acquiring a new language.

Similarly, Purdy (2008) maintains that inviting students to conversations about texts through questioning, teaching vocabulary effectively, and structuring situations where students can engage in collaborative talk about text shape and extend the use of oral language. It is clearly important to keep in mind that students can read text even the complex one with sufficient supports that lighten up the load, especially at earlier levels of proficiency (Kibler et al., 2015).

For example, teacher's questioning in Purdy's (2008) study may invite broader and deeper thinking to check factual information and understanding. A response by a student named Angela in this study to the question about the text posted by the teacher, "What does the legend explain?" allowed the teacher to locate the gap in students' understanding of the text. Other students then may take up her answer and elaborate it to be their own, and so does it develop in a snowball fashion. The teacher most of the time also stepped out of the discussion to allow students having more opportunities to use language for authentic purposes and engage more in the discourses with more proficient speakers of English.

More importantly, teachers should make sure that the scaffolding embedded in the texts and the discussion should activate and build background knowledge of the students, so that they have ample opportunities to work with peers and experience the elements of text with multiple modalities (Kiebler et al., 2015). After the students have full account of background knowledge, the scaffolding can be extended to help them deepen their comprehension.

Complex text has a variety of dimensions (Messer et al., 2012) starting from the vocabulary, grammatical features, levels of meaning, to the structure of text in particular genre. Proper scaffoldings and modalities will help students to unfold this complexity and arrive at a better understanding of the text.

Finally, we argue that students may benefit from instructional practice that promotes more opportunities for them to use language in meaningful context (i.e. conversation or discussion about text). It will in turn develop their oral language skills, which is an area that they most lack of and at the same time foster their reading comprehension. It is in line with Iddings et al. (2009) that although the teachers do not speak the students' native language to provide needed support in their first language, meaningful connection to texts can still be feasible through supportive interactions.

Vygotsky (1978) has also written that learning itself is a mediated activity through social, cultural, and historical factors. When students are provided with assistances within their proximal development, they may develop new understanding and use novel concepts in multiple applications. Language-rich classrooms support students' engagement with the texts and develop a strong sense of meaning making in a social context (Bauer \& Manyak, 2008). We would also add to Martinez et al.'s (2014) review that explicit teaching of vocabulary is indeed important to support oral language development, but implementing practice that orchestrated literacy skills in an integrated way is more meaningful for both the language learning and acquisition processes.

\section{Making Connection between the Students' Own Culture and the Target Culture}

Culture is inseparable part of learning, particularly second-language learning. What cultural information and whose culture brought to the classroom need to be carefully examined (Lantolf, 2011). As identified earlier that insufficient background knowledge on the target culture may hinder access 
for students to grasp meaning of the text, especially when their own culture is disregard during the process of learning (Drucker, 2003; Hite \& Evans, 2006; Toppel, 2015).

As such, it is crucial for teachers to make connection between the students' culture and the target culture read in the text. There is a growing interest in the literature that solidifies the significance of culturally-relevant texts for learning (e.g. Kganetso, 2016; Louie \& Sierschynski, 2015; Sharma \& Christ, 2017) and the notion of culturally-linguistically relevant pedagogy to facilitate the English and literacy learning in the mainstream classroom (see e.g. Islam \& Park, 2015; Ladson-Billings, 1995; Lucas \& Villegas, 2013; Lucas, Oliveira, \& Villegas, 2014; Lucas, Villegas, \& Freedson-Gonzalez, 2008; Nash, Panther, \& Arch-Boardman, 2017; Oliveira \& Shoffner, 2009).

\section{Selecting Culturally-Relevant Text}

The idea of including or integrating cultural information in texts in the mainstream classroom lies in the underpinning notion that children need to develop particular schema, including cultural schema and background knowledge to comprehend text (Drucker, 2003). In particular, they will easily understand meaning of the text that appears similar or close to their own culture.

Sharma and Christ (2017) argued that a greater diversity of perspective and culture within the classroom can be represented in texts that reflect such diversity. They then provided a framework for teachers to select culturally relevant texts, which begins with the need to recognize of whether culturally responsive instruction is appropriate for the classroom. This step suggests teachers to reflect on and evaluate their own belief and framework of the teaching and learning.

The second step is to collect more information about the students' lives in order to have a comprehensive knowledge about what to bring to the table. It can be done through, for example personal interview, personal story projects, or inviting student to collect text that are culturally relevant to them. Next, teachers can begin the search for culturally relevant text based on the information gathered from the previous steps and select some for use in the classroom.

This process might be tricky and challenging given the fact that there might be thousands of them out there. Using systematic search and rubric with certain selection criteria to critically evaluate some items would be helpful. Finally, teachers should identify critical and personal response for discussion in the class (Sharman \& Christ, 2017).

The above framework provides insights for teachers that are often underprepared to engage with students in the mainstream classroom. In a similar vein, Kganetso (2016) argued that compared to other genres of text, access to procedural and informative/explanatory genres that are culturally relevant is way too limited. In fact, informational texts have been used largely to develop students' expertise in content area, including in language and literacy learning.

As students progress through school, they are required to rely more on informational texts to acquire knowledge across disciplines (e.g., science experiments, history books). As such, steps as suggested by Sharma and Christ (2017) may be followed with an extra emphasis on familiar content and genrespecific characteristics and processes, not just relevance or responsiveness.

Louie and Sierschynski (2015), in addition, suggested another way to incorporate cultural information in the text by the use of wordless picture book. Basically, this type of book poses all the literary elements and narrative structures as found in written texts but is delivered through series of illustrations. It allows students to engage with complex contents as they discuss complex meanings toward oral language and construct the written text of their own. 
Teacher's role is to: (1) help readers identify the plot and structure, the characters, and the setting of the book, (2) support their decisions using details from the book, and (3) help readers orally retell the story, using details of the illustrations to construct a text (Louie \& Sierschynski, 2015).

\section{Incorporating Culturally-Relevant Teaching Pedagogy}

As culturally relevant texts are available, what instructional practices should be carried out in the classroom and how? Toppel (2015) suggested that culturally responsive teaching contains components that addressed the needs of students and diversity of today's classroom, especially in implementing core reading program.

According to Ladson-Billings (1995), as a framework or an approach of teaching, culturally relevant pedagogy should meet at least three criteria: (1) an ability to develop students' academic achievements, (2) nurture and develop cultural competence, and (3) develop sociopolitical and critical awareness. This concept is oriented within the relation of self, other, social context, and knowledge construction. Stairs (2007) added that culturally responsive pedagogy views diversity an asset that enriches the learning of all students, not a deficit to overcome. The term has been used interchangeably with "relevant" or "sustaining", but responsive simply means reacting appropriately in the instructional context.

Nash et al. (2017) maintain that culturally responsive teaching fosters students' linguistic and cultural fluidity with all of the languages they speak. This framework may be applicable in any other teaching methods that best work for teaching. The salient feature of implementing it is the recognition of students' own culture to learn language, literacy, and other culture by giving them agency during the process of knowledge construction.

In addition, Lucas et al. (2008) suggested some strategies that can be implemented, including:

- Using extra-linguistic supports

- Supplementing and modifying written text

- Supplementing and modifying oral language

- Giving clear and explicit instructions

- Facilitating and encouraging the use of student's native languages

- Engaging students in purposeful activities in which they have many opportunities to interact with

others and negotiate meaning, and

- Minimizing the potential for anxiety in a mainstream classroom.

This framework has been developed into some orientations, knowledge, and skills that teachers should possess (Lucas et al., 2014; Lucas \& Villegas, 2013; Oliveira \& Shoffner, 2009) as in the following:

1. Sociolinguistic consciousness

2. Value for linguistic diversity

3. Inclination to advocate for ELLs

4. Learning about students' language backgrounds, experiences, and proficiencies

5. Identifying the language demands of classroom discourse and task

6. Applying key principles of second language learning, and

7. Scaffolding instruction to promote LL's learning

To conclude, today's classroom may consist of very diverse students with various linguistic and cultural backgrounds. This diversity should be seen as a resource for learning in which its recognition in the class might facilitate the language and literacy development. As such, teachers should make sure that the students have access to culturally relevant texts that help them build necessary schema and 
background knowledge to construct meaning of the text. Additionally, teachers should make connection between the students' own culture and the target culture being learnt.

This connection can be built through the implementation of culturally responsive/relevant teaching in which issues around self, culture, larger social-political context, and knowledge construction are made visible during the process of learning. That being said, this review supports Martinez et al. (2014) that culturally compatible classroom is needed for students to achieve higher rates of literacy attainments.

\section{Strengthening Academic Language}

There has been a growing consensus in the literature that students need to develop academic language in order to have full participation in the mainstream classroom (Anderson \& Loughlin, 2014; August, Artzi, \& Barr, 2006; Leighton et al., 2017; Martinez et al., 2014). According to Ranney (2012) academic language or academic English is based on Cummin's (1979) formulation of Basic Interpersonal Conversational Skills (BICS) and Cognitive Academic Language Proficiency (CALP).

It takes several years for students to develop academic language, i.e. about 5-7 years of formal schooling (August \& Shanahan, 2006; Cummin, 2009). Simply put, academic language is the language of school that commonly found in books, assignments, and tests. The constructs of academic language may contain academic vocabulary, grammatical features at different level, and forms of language at different functions and register (Ranney, 2012).

Moreover, August et al. (2016) argued that vocabulary knowledge is an important determinant of reading comprehension and it is required by the Common Core State Standard for English Language Arts for students to acquire general academic and domain-specific vocabulary and phrases found in texts relevant to grade level topics and subject areas.

As a case in point, Anderson and Loughlin (2014) examined the academic language used by students in language arts lessons with and without classroom drama as the instructional approach. Data from observation, interview, and language sampling in the classroom showed that the students used significantly higher rates of English academic language forms. Additionally, the classroom teacher used more dialogic discourse, measured by increased rates of requestive and responsive speech acts during drama, as compared with conventional lessons.

Similarly, Leighton et al. (2017) argued that one the challenges that same students faced in reading complex expository texts is lack of academic language. They then described an intervention designed to engage and motivate students with varying learning profiles as they developed conceptual knowledge and academic language. They suggested that in teaching complex expository text, teachers should consider the following principles: (1) establish contexts that support cognitively complex activity, (2) cultivate engagement in reading and learning, and (3) build language and knowledge simultaneously. To this end, there has been considerable research findings suggesting that academic language should be a focus of teaching students in the mainstream classroom.

However, we argue that academic language is an area that yet to be developed by the research community given the fact that limited number of studies found. A little is known about its relationship to other measures of literacy components, like reading comprehension. If teaching academic vocabulary is crucial is there any threshold of vocabulary richness that students should acquire to close the gap between them and their English monolingual peers?

At this point, none of this review or Martinez et al.'s (2014) work is able to discover the difference of academic language mastery between ELLs and their English monolingual peers. Questions about the best practices to teach academic language also remain open for further investigation. Finally, we argue 
that knowledge about the complexity of academic language both in spoken and written forms is important to consider in developing the English and literacy skills, but educators should push the teaching beyond this point because reading itself is the orchestration of multiple skills.

\section{Systematic and Explicit Teaching of Vocabulary}

There is established evidences that that vocabulary learning plays a pivotal role in children' literacy development because words allow them to effectively communicate and understand text, in which then are essential to facilitate the process of learning in general (Ingraham, 2014; Larson, 2014; Lessaux et al., 2010; Silverman el al., 2013; Taboada, Bianco, \& Bowerman, 2012).

Research to date also adds to the knowledge base reviewed previously that ELLs seem to lag behind their English monolingual peers in vocabulary development, which then might result in failing other literacy components like reading comprehension, and thus particular instruction or intervention in this literacy component is considered crucial (August \& Shanahan, 2006; Goldenberg, 2011; Taboada, 2009).

Such instructional approaches found in the literature, however, are varied in respect with the depth and breadth of the words, types of vocabulary, and explicitness on specific vocabulary (e.g. academic vocabulary). There is a consensus though that students might learn better through instructional approach that is explicit and emphasizes word meaning in contexts, as well as provides multiple opportunities for repetition (Lessaux et al., 2010; Silverman et al., 2013).

We should also argue that although teaching specific component of literacy explicitly is important (e.g. vocabulary), and there is considerable evidence supporting this notion, focusing on integrative or holistic components of literacy is more crucial. As Goldenberg (2011) has written that "competent reading is an integrative and functional act, that is, it requires successfully combining (integrating) a number of skills for the purpose of accomplishing concrete goals (functions)" (p. 694). ELLs indeed need much more than just a single skill to succeed in reading and academically as it is also true for all students.

\section{Conclusion}

In this paper, we critically review the existing literature to identify issues relative to the English and literacy learning of ELLs in the mainstream classroom and discuss the ways teachers should engage with them to support their development. This review extends the work of Martinez et al. (2014) by building on current scholarship and focusing specifically on elementary grades. The main goal of this review is to provide educators with cutting-edge evidence on how to promote the English and literacy learning of ELLs and direct future researchers to push the field forward.

\section{References}

Anderson, A. \& Loughlin, S.M. (2014). The influence of classroom drama on English lear Anderson, A. \& Loughlin, S.M. (2014). The influence of classroom drama on English learners academic language use during English language arts lessons. Bilingual Research Journal, 37(3), 263-286.

August, D., Artzi, L., \& Barr, C. (2015). Helping ELLs meet standards in English language arts and science: An intervention focused on academic vocabulary. Reading and Writing Quarterly, 32(4), 373-396.

August, D., McCardle, P., \& Shanahan, T. (2014). Developing literacy in English language learners: Findings from a review of the experimental research. School Psychology Review, 43(4), 490-498. 
August, D., \& Shanahan, T. (2006). Developing literacy in second-language learners: Report of the national literacy panel on language-minority children and youth. NJ: Lawrence Erlbaum Associates, Inc.

Avalos, M., Plasencia, A., Chavez, C., \& Rascon, J. (2007). Modified guided reading: Gateway to English as a second language and literacy learning. The Reading Teacher, 6(14), 318-329.

Bauer, E.B., \& Manyak, P.C. (2008). Creating language-rich instruction for English-language learners. The Reading Teachers, 62(2), 176-178.

Cummins, J. (2009). Literacy and English-language learners: A shifting landscape for students, teachers, researchers, and policy makers. Educational Researcher, 38(5), 380-385.

Cole, M.W. (2014). Speaking to read: Meta-analysis of peer-mediated learning for English language learners. Journal of Literacy Research, 46(3), 358-382.

DelliCarpini, M. (2008). Modifying lessons for English language learners. The English Journal, 98(2), 98-101.

DelliCarpini, M., \& Gulla, A.N. (2016). Working with English language learners in the mainstream English language arts classroom through collaboration and two-way content-based instruction. In Oliveira, L. C., \& Shoffner, M. (Eds.), Teaching English language arts to English language learners: Preparing pre-service and in-service teachers (pp. 79-105). FL: Palgrave Macmillan.

Drucker, M.J. (2003). What reading teachers should know about ESL learners. The Reading Teacher, 57(1), 22-29.

Fitzgerald, J., Elmore, J., Reyea, J.U., Hiebert, E.H., \& Stenner, A.J. (2016). Has first-grade core reading program text complexity changed across six decades? Reading Research Quarterly, 51(1), 7-28.

Flynn, N. (2007). Good practice for pupils learning English as an additional language: Lessons from effective literacy teachers in inner-city primary schools. Journal of Early Childhood Literacy, 7(2), 177-198.

Frantz, R.S., Starr, L.E., \& Bailey, A.L. (2015). Syntactic complexity as an aspect of text complexity. Educational Researcher, 44(7), 387-393.

Greenfader, C.M., Brouillette, L., \& Farkas, G. (2014). Effect of a performing arts program on the oral language skills of young English learners. Reading Research Quarterly, 50(2), 185-203.

Hite, C., \& Evans, L. (2006). Mainstream first-grade teachers' understanding of strategies for accommodating the needs of English language learners. Teacher Education Quartely, Spring, 89-110.

Iddings, A.C.D., Risko, V.J., \& Rampulla, M.P. (2009). When you don't speak their language: Guiding English language learners through conversation about text. The Reading Teacher, 63(1), 52-61.

Islam, C., \& Park, M. (2015). Preparing teachers to promote culturally relevant teaching: Helping English language learners in the classroom. Multicultural Education, Fall, 38-44.

Jia, F., Gottardo, A., Koh, P.W., Chen, X., \& Pasquarella, A. (2014). The role of acculturation in reading a second language: Its relation to English literacy skills in immigrant Chinese adolescents. Reading Research Quarterly, 49(2), 251-261.

Jimenez, R.T., David, S., Pacheco, M., Risko, V.J., Pray, L., Fagan, K., \& Gonzales, M. (2015). Supporting teachers of English learners by leveraging students' linguistic strengths. The Reading Teacher, 68(6), 406-412.

Kibler, A., Walqui, A., \& Bunch, G. (2015). Transformational opportunities: language and literacy instruction for English language learners in the Common Core Era in the United States. TESOL Journal, 6(1), 9-35.

Kganetso, L.M. (2016). Creating and using culturally relevant informational texts. The Reading Teacher, 70(4), 445-455.

Ladson-Billings, G. (1995). Toward a theory of culturally relevant pedagogy. American Educational Research Journal, 32(3), 465-491. 
Lantolf, J.P. (2011). The sociocultural approach to second language acquisition: Sociocultural theory, second language acquisition, and artificial L2 development. In D. Atkinson (ed.). Alternative Approaches to Second Language Acquisition (pp. 24-47). London: Routledge.

Lefstein, A., \& Snell, J. (2011). Promises and problems of teaching with popular culture: A linguistic ethnographic analysis of discourse genre mixing in a literacy lesson. Reading Research Quarterly, 46(1), 40-69.

Leighton, C.M., O'Brien, L.M., \& Giunco, K. (2017). Advancing English learners' disciplinary knowledge and academic language using complex expository text. The NERA Journal, 52(1), 718.

Louie, B., \& Sierchynski, J. (2015). Enhancing English learners language development using wordless picture books. The Reading Teacher, 69(1), 103-111.

Lucas, T. (2011). Language, schooling, and the preparation of teachers for linguistic diversity. In Lucas, T. (Ed.), Teacher preparation for linguistically diverse classrooms: A resource for teacher educators (pp. 3-17). NY: Routledge.

Lucas, T., Oliveira, L.C., \& Villegas, A.M. (2014). Preparing linguistically responsive teachers in multilingual contexts. In Maboob, A., \& Barrat, L. (Eds.), Englishes in multilingual contexts (pp. 219-230). NY: Springer.

Lucas, T., \& Villegas, A.M. (2013). Preparing linguistically responsive teachers: Laying the foundation in preservice teacher education. Theory into Practice, 52, 98-109.

Lucas, T., Villegas, A.M., \& Freedson-Gonzalez, M. (2008). Linguistically responsive teacher education: Preparing classroom teachers to teach English language learners. Journal of Teacher Education 59(4), 361-373.

Martin-Beltran, M., Tigert, J.M., Peercy, M.M., \& Silverman, R.D. (2017). Using digital texts vs. paper texts to read together: Insights into engagement and mediation of literacy practices among linguistically diverse students. International Journal of Educational Research, 82, 135-146.

Martinez, R.S., Harris, B., \& McClain, M.B. (2014). Practices that promote English reading for English learners (ELs), Journal of Educational and Psychological Consultation, 24, 128-148.

Mesmer, H.A., Cunningham, J.W., \& Hiebert, E.H. (2012). Toward a theoretical model of text complexity for the early grades: Learning from the past, anticipating the future. Reading Research Quarterly, 47(3), 235-258.

Nash, K., Panther, L., \& Arce-Boardman (2018). La historia de mi nombre: A culturally sustaining early literacy practice. The Reading Teacher, 71(5), 605-609.

National Assessment of Educational Progress (NAEP). (2013/2015). Fast facts data on English learners (ELs). Retrieved from https://ncela.ed.gov/fast-facts

Oliveira, L.C., \& Shoffner, M. (2009). Addressing the needs of English language learners in an English education methods course. English Education, 42(1), 91-111.

Pray, L., \& Jimenez, R.T. (2009). Literacy and English-language learners: What researchers and policy makers should know. Educational Researcher, 38(5), 380-385.

Purdy, J. (2008). Inviting conversation: Meaningful talk about texts for English language learners. Literacy, 42(1), 44-51.

Pyle, N., Vasquez, A.C., Kraft, B.L., Reutzel, D.R., Olszeski, A., Segura, H., ... Pyle, D. (2017). Effects of expository text structure interventions on comprehension: A meta-analysis. Reading Research Quarterly, 52(4), 469-501.

Ranney, S. (2012). Defining and teaching academic language: Developments in K-12 ESL. Language and Linguistic Compass, 6(9), 560-574.

Sharma, S.A., \& Christ, T. (2017). Five steps toward successful culturally relevant text selection and integration. The Reading Teacher, 71(3), 295-307.

Stairs, A.J. (2007). Culturally responsive teaching: The Harlem renaissance in an urban English class. English Journal, 96(6), 37-42.

Toppel, K. (2015). Enhancing core reading programs with culturally responsive practices. The Reading Teacher, 68(7), 552-559. 
Quiros, A.M., Lara-Alecio, R., Tong, F., \& Irby, B. (2012). The effect of a structured story reading intervention, story retelling and higher order thinking for English language and literacy acquisition. Journal of Research in Reading, 35(1), 87-113.

Vygotsky, L.S. (1978). Mind in society: The development of higher psychological processes. Cambridge, MA: Harvard University Press. ners academic language use during English language arts lessons. Bilingual Research Journal, 37(3), 263-286. 